\title{
Modeling the contributing factors of desertification and evaluating their relationships to the soil degradation process through geomatic techniques
}

\author{
P. Shoba and S. S. Ramakrishnan \\ Institute of Remote Sensing, Anna University, Chennai, India \\ Correspondence to: P. Shoba (shoba84.geog@gmail.com) \\ Received: 19 November 2015 - Published in Solid Earth Discuss.: 9 December 2015 \\ Revised: 22 February 2016 - Accepted: 22 February 2016 - Published: 8 March 2016
}

\begin{abstract}
Desertification is a prolonged type of land degradation which converts the productive ecosystem to a fragile one by two crucial factors, namely, climate and negative human intrusion. The present study concentrates on identifying the causative factors of desertification, namely temperature, wind, rainfall scarcity and human pressure. It also concentrates on distinguishing the desertified land from degraded land and assessing the way in which the soil degradation process becomes accelerated by these factors, by employing data sets such as meteorological data and Landsat ETM+ (Enhanced Thematic Mapper) and OLI (Operational Land Imager) satellite images of the crop-growing period (JuneOctober) in geostatistical methods and newly proposed remote sensing models, which yielded good accuracy with in situ observations $\left(R^{2}=0.8\right)$. The study was centered on two time periods, 2001-2011 (11 years) and 2012-2015 (4 years). In rainfall-temperature/drought-induced desertified region, the rate of salt-affected soils increased significantly from 12 to $58 \%$ (2001-2015) due to the presence of native fluoride concentration and extreme temperature events. The region has also been experiencing high soil moisture stress ( 5 to $33 \%$ ) because of the insufficient occurrence of rainfall over a period of time. A longer term exacerbation of soil moisture stress (19 to $90 \%$ ) has been noted in the areas that were susceptible to wind-induced desertification, due to a high evaporation rate caused by extreme wind events for a substantial period. High human-induced soil salinity (36\%), human occupancy $(16 \%)$, followed by moisture stress $(7 \%)$ are observed in the human-affected region because of growing population and improper land management of the land that is already fragile.
\end{abstract}

\section{Introduction}

Desertification is defined as the "degradation of the soil, landscape and bio-productive terrestrial system, in arid, semiarid and subhumid areas resulting from several factors including climate change and human activities" (UNCCD, 1994). Desertification is generally perceived as a "slow" hazard in semiarid regions, initially induced by climatic factors, and becoming accelerated when combined with human actions (population pressure, intensive land use, improper land management etc.) and the active state of parent material prevailing in a longer time frame (Lin and Tang, 2002), which causes an adverse effect on people and the ecological system. Drought-induced desertification is aggravated due to the spatiotemporal variations in rainfall, temperature, wind and solar radiation (D'Odorico et al., 2013) and human-induced desertification is exacerbated due to the ever-increasing population, along with food and fodder demand, which results in socioeconomic pressure on the land (Wang et al., 2010). This situation demonstrates that desertification is not only a global concern but also a local problem (Salvati et al., 2013) which has to be addressed in order to mitigate the desertification process (Fleskens and Stringer, 2014).

Globally, this phenomenon affects about 1.9 billion hectares of land and 250 million people (Low, 2013). Among many events which affect earth's environment and ecosystem, drought often has a direct association with desertification (Shewale and Shravan, 2005). Poor land management during periods of unusually dry weather can cause loss of vegetation, which in turn leads to desertification (Sharmia, 2008). Desertification is the end stage of the land degradation process (Hill et al., 2005) which ultimately affects the 
economical and biological productivity of the land (Izzo et al., 2013) and leads to economical stress to the vulnerable population (Bisaro et al., 2014) by degrading soil fertility completely.

Though desertification-inducing factors had an immense negative effect on many environmental components, soil is a prime component that becomes deteriorated by the process. Land degradation caused by the removal of vegetation is perceived as a consequence of soil degradation (Akhtar-Schuster et al., 2011). Once the physical, chemical and biological properties of the soils start degrading, natural regeneration is not possible in a human lifespan (UNCCD, 2012); hence soil is termed as a nonrenewable resource. Roxo et al. (2001) have defined desertification in relation to soil degradation through the continuous loss of soil fertility by damage of structure and composition of the soil which ultimately affects the sustainable agricultural production. Since desertification impacts soil directly, it is necessary to identify the prime causative factors which accelerate desertification and evaluate the soil degradation process which is stimulated by these factors, in order to protect this precious resource before it loses its capacity entirely.

Remote sensing technology is successfully applied to the process of monitoring desert expansion and the assessment of factors that cause desertification (Hanan et al., 1991). In recent days, a range of desertification processes has been successfully analyzed and addressed, through the application of remote sensing techniques (Barbero-Sierra et., 2015; Miao et al., 2015; Wang et al., 2015; Torres et al., 2015; Yan et al., 2015; Xu et al., 2015). The land degradation of arid and semiarid zones, often called desertification when it is irreversible in form, and the main factors of this phenomenon being either climate- or human-induced, has been much debated since the mid-1970s (Rasmussen et al., 2001). Climate fluctuations and human activities together induce desertification in semiarid regions; their individual impacts should be assessed in detail in order to resolve the ambiguity over which of them is the primary cause (Runnstrom, 2003; Wang et al., 2006). Besides rainfall, temperature and wind are also important climatic factors which can accelerate desertification through the process of evaporation. Wind speed, combined with temperature, is a key element to assess the moisture stress of exposed soil and vegetation in arid and semiarid regions. Soil moisture stress results from the occurrence of high daytime wind speed (Jacobson, 1999). The higher wind speed does not help the soil and plants to retain moisture content, and thus contributes to strong vegetation decline. Weishou et al. (2011) found a strong negative correlation between the Normalized Difference Vegetation Index (NDVI) and mean wind speed, which shows that wind speed and vegetal degradation effects are dependent on each other.

The rate of rainfall distribution in the western part of the study region is hampered by the Western Ghats, as it is situated on the leeward side, which results in poor vegetal status over a period of time. Therefore the influence of tem- perature and wind is expected to be dominant in the western part of the study region. The condition is reversed in the eastern part of the study area, where the rate of rainfall is adequate and temperature is moderate. There have not been many reports that emphasize the identification of the accelerating factor of desertification by considering wind and temperature along with NDVI and rainfall so far. This is the first time the spatial correlation models have been developed with the combination of wind speed, NDVI and rainfall in order to predict the wind-temperature, rainfall-temperature (drought) and human-affected regions of desertification.

Furthermore the present study identifies and extracts the completely desertified area from the degraded area with the help of the recent short-term negative vegetation trend, which was lacking in the previous studies. The reason behind the incorporation of the recent short-term vegetal trend in the present study is that "in semiarid regions the ecosystem retains its consistency and ability to respond to the recurrence of the rainy season" (Kassas, 1977). If the degraded land does not respond to adequate rain, the situation is termed as desertification.

Desertification-inducing factors (temperature-, wind-, rainfall- and human-inducing factors) have an immense effect on soil fertility in semiarid regions. After the identification of the causative factors and extraction of desertified lands, the study also focuses on the crucial and suspected degradation components invoked by four base factors on the desertified lands that make the soil of these regions entirely unproductive/irreversible. The study region has naturally inherited high fluoride content from the groundwater. A positive correlation between fluoride and $\mathrm{pH}$ indicated that alkaline conditions improved the solubility of fluoride (Adhikary et al., 2014). Hence, the groundwater salinity has been carried to the subsurface and some surface levels of the soil through capillary action, and during the extreme temperature event, the saline water is evaporated and salt remains accumulated. The climatic factors such as temperature, rainfall and wind have been combined with the active presence of natural fluoride, which greatly influences the soil desertification process.

According to the facts, the theoretical prediction is formulated as the area that is affected by desertification due to the high rainfall-temperature/drought factor which should have definitely experienced soil salinity because of extreme temperatures, native fluoride content and soil moisture stress at surface and subsurface level (root zone) due to rainfall scarcity; similarly, the desertified area due to high wind speed would have experienced soil moisture stress at the surface level.

Hence the testable directional hypothesis was formed in order to prove the above-stated theoretical prediction. A directional hypothesis is usually formed in such a way that predicts the specific relationship between the components and direction of that relationship. After the execution of the testable hypothesis, the empirical multispectral models have 
been proposed in the current study to extract the soil salinity and moisture stress from the images with reasonable accuracy.

The prime objective of the study is (i) to identify and differentiate different zones of degradation and desertification with respect to rainfall-temperature/drought, wind and anthropogenic factors using a geostatistical model; (ii) to form the hypothesis in such a way that proves the theoretical prediction of what soil degradation process can be expected from each zone of desertification; (iii) to quantify and assess the possible soil degradation processes, namely soil moisture stress and salinity, at surface and subsurface levels through remote sensing models and techniques; (iv) to validate the work to assure the reliability of the geostatistical and remote sensing models through in situ observations.

\section{Materials and methods}

\subsection{Study region and prevailing problems}

Dharmapuri is located in the northwestern climate zone of Tamil Nadu, India. It lies between $11^{\circ} 47^{\prime}$ and $12^{\circ} 33^{\prime} \mathrm{N}$ and $77^{\circ} 28^{\prime}$ and $76^{\circ} 45^{\prime} \mathrm{E}$. The annual potential evapotranspiration rate in this region is $1727 \mathrm{~mm}$, compared to annual precipitation of $825 \mathrm{~mm}$. It is a dry and semiarid production system (Fig. 1). The study region has been facing a maximum temperature of about $37^{\circ} \mathrm{C}$ in the months of AprilMay. Rhodustalfs, Ustropepts and Rhodic Paleustalfs (Soil Survey Staff, 2014) are the dominate soil taxa found in the site with a high presence of loam and clay which stimulates the capillary action while experiencing high temperature. Sorghum, finger millet and little millet are the major field crops of the Dharmapuri district, whose spatial distribution is about 34000 ha, which supports $70 \%$ of the population. The socio-economic condition of the region is very poor due to poor rainfall and frequent monsoon failure, thus leading to drought in many parts of the region (Anbazhagan et al., 2000).

The district also faces strong salinization, affecting $2 \%$ of land. About $1 \%$ of land is affected by waterlogging and it is proved with the presence of hard pans (Fig. 5e). The entire region suffers from water scarcity and out of five taluks, four are over-exploited (Central Ground water Board Report, 2009). The presence of fluoride is more than the permissible limit (above $1.5 \mathrm{mg} \mathrm{L}^{-1}$ ) in the study region (Sendesh et al., 2011; Ramesh and Vennila, 2012). A positive correlation between fluoride concentration and $\mathrm{pH}$ indicated that alkaline conditions improved the solubility of fluoride (Adhikary et al., 2014a). Groundwater in aquifers in general is slightly alkaline in nature (Central Ground water Board Report, 2009). The erratic climatic events, socioeconomic developments and unsustainable agricultural practices in the past decades exert strong pressure on the fertile land of the study region.
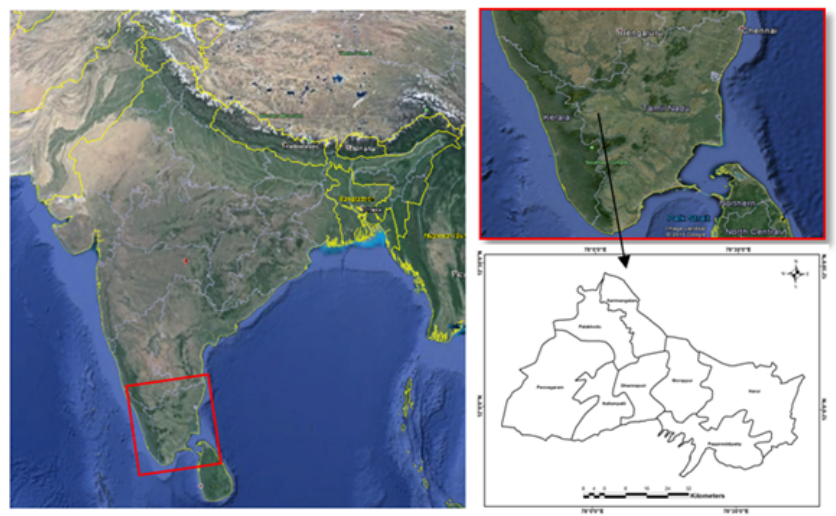

Figure 1. Study area - Dharmapuri district of Tamil Nadu, India. It is a typical example of semiarid regions across the world where $70 \%$ of the population rely on dry land agriculture. The annual evapotranspiration rate exceeds the rate of rainfall because of its locality under rain-shadow region of the Western Ghats. Prevalence of extreme temperatures, native fluoride in nature and unsustainable agricultural practices have caused the region to experience drought, which often leads to desertification.

\subsection{Satellite data}

Since MODIS (Moderate Resolution Imaging Spectroradiometer) and NOAA AVHRR satellites have high temporal resolution, they have been adopted for long-term change detection, land degradation and desertification analysis so far by various researchers across the world. However, the limiting factor which hinders the applicability to employ those images in the subregional-level assessment is their low spatial resolution. Therefore, moderate spatial resolution with long-term temporally available images are required to assess the phenomena at subregional level. Landsat satellite images have the longest spatial record for land observation (Williams et al., 2006). Therefore, the present study is carried out using ETM+ (Enhanced Thematic Mapper) and OLI (Operational Land Imager) images on board Landsat 7 and 8 Mission from 2000 to 2015. A total of eight bands starting from 30 blue $(0.441-0.514 \mu \mathrm{m})$ to $15 \mathrm{~m}$ panchromatic $(0.515-0.896 \mu \mathrm{m})$ of the electromagnetic spectrum are utilized in the ETM+ mission, whereas the arrangements and the inclusions of bands are slightly modified in the OLI mission. Band 1 is a deep blue band for coastal/aerosol studies and band 11 is a shortwave infrared band for cirrus detection in the OLI mission.

The two satellites are in a sun-synchronous, near-polar orbit at $705 \mathrm{~km}$ altitude and have the moderate spatial resolution of $30 \mathrm{~m}$ for multispectral bands. ETM+ data of path no. 143 path and row no. 52 were collected from 2001 to 2012 and OLI images were collected from 2013 to 2015 from the Glovis online free resource center. Bands were stacked and the subset operation was performed in order to clip the images with respect to the study area. From 2004-2012 the Landsat 7 mission acquired the data using the Scan Line Cor- 
rector (SLC) off mode. SLC images were collected for the corresponding years, spatially corrected using focal analysis and spectrally equalized using a histogram equalization method to prepare the data for further geospatial analysis as illustrated below.

\subsection{Meteorological data and desertification phase identification}

Daily meteorological data sets such as rainfall, minimum temperature, maximum temperature, wind speed, solar radiation and relative humidity from 2001 to 2015 have been collected from Centre for Climate Change and Adaptation Research, Anna University, India. Dharmapuri is one of the districts of Tamil Nadu, India, which is affected by the kharif season or southwest monsoon rain (June-October). Therefore, the crop growth is considerably high from June to October. There are six meteorological stations, distributed in and around the study region. Plotted points are interpolated using the inverse distance weighting method with same resolution ( $30 \mathrm{~m}$ cell size) as the Landsat data. The minimum temperature, maximum temperature, wind speed, solar radiation, relative humidity and rainfall raster of different months of growing season are then averaged to obtain the mean values of growing season of each year.

Land degradation to desertification phase identification plays a vital role before an assessment of desertification can begin. The phase can be initially identified through rainfall and temperature distribution. The time span of land degradation/drought has to be identified in order to recognize the progress of desertification. From 2006 to 2011 there was a significant decline in rainfall and increment in temperature followed by sudden, high rainfall which occurred in 2012 (Fig. 2). Therefore, the land degradation probably occurred in the 2006-2011 time frame.

Soil degradation has a more direct relationship with desertification than other environmental parameters. The degraded soil cannot be reversed when the natural degradation component and anthropogenic activities are prolonged for more than a decade. There are many soil degradation processes which are irreversible in nature and may have a direct association with desertification. If the degraded soil is not regenerated from the high rainfall that began in 2012 and continued until 2015 (4 years), then it is termed as soil desertification, otherwise it is just seen as degradation.

The research question arose here as follow. By which component have the soil desertification processes been accelerated? The research question was answered by formulating the hypothesis. Soil salinity and soil moisture stress is hypothesized in the study region based on the climatic prevalence (less rainfall and fewer extreme temperature events), geological functions (nature of the parent material - fluoride concentration) and human pressure. The soil desertification processes which were active during both the periods were analyzed, quantified and extracted with respect to the

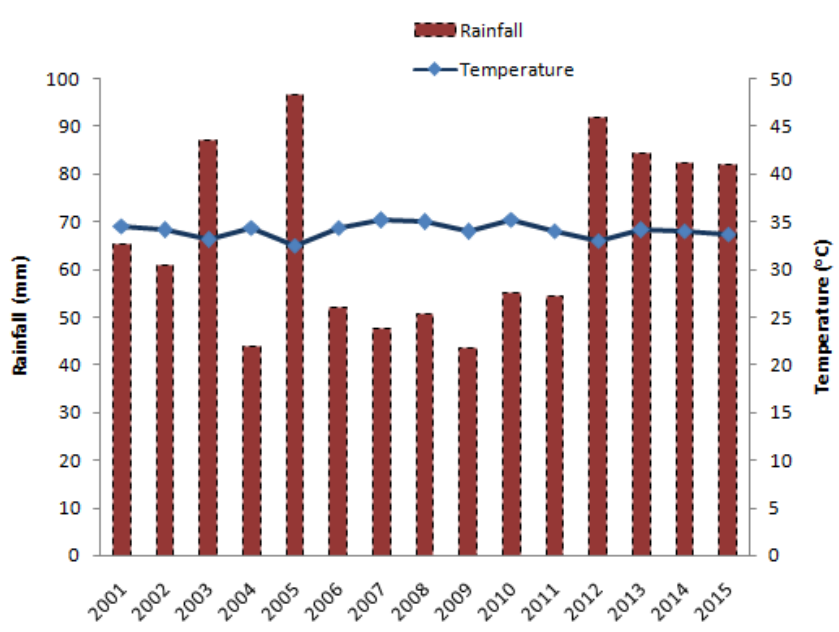

Figure 2. Climate diagram for one of the meteorological stations (Nallampalli $12.34^{\circ} \mathrm{N}, 77.88^{\circ} \mathrm{E}$ ) of the study region at $349 \mathrm{~m}$ elevation - rainfall vs. temperature for the crop-growing period (JuneOctober) from 2001 to 2015 . The significant drought period was observed from 2006 to 2011, followed by adequate rainfall distribution (2012-2015) which is appropriate for crop production. If the degraded land (2006-2011) is not renewed or regenerated after receiving sufficient rainfall, which occurred from 2012 to 2015, then the situation is termed as desertification, otherwise it is just seen as degraded land.

prime inducing components (temperature-, wind-, rainfalland human-inducing components) after the successful execution of the hypothesis.

\subsection{NDVI topographical normalization}

Before estimating the NDVI (Normalized Difference Vegetation Index), the bands of the images have to be topographically normalized in order to eliminate the effects from the shadowed region on NDVI images. Bands 3 and 4 of ETM+ and OLI are topographically normalized using modified cosine correction (Meyer et al., 1993) to eliminate the illumination variation which hampers the ability to discriminate ground features, as the same features will have different spectral responses among shadowed and non-shadowed regions. It is very important to eliminate the topographical effects in the present study as the correlation analysis is highly affected by the shadow region. For instance, the water body in the NDVI and rainfall have no correlation over a period of time, thus the result of the correlation analysis should be zero in those places. Some locations in the eastern part of the region are covered by shadow because of the presence of vegetation $(2 \%)$ on the elevated terrain. Due to the presence of vegetation and the occurrence of moderate rainfall, the area has to be shown as highly correlated. However, the shadow region is considered as a water body by the model because of the spectral coincidence of shadow region and water body, and the resultant correlation is zero (no correlation). Hence the 
shadowed vegetation has a high possibility of being wrongly estimated as having no correlation if the topographical effects are not eliminated. After applying the normalization to the bands, the eastern and western parts (hilly region) of the NDVI have been well enhanced.

\subsection{Spatial regression model}

A strong linear trend was identified between the NDVI and 3-months' cumulative rainfall (Nicholson et al., 1990). Since the rainfall and NDVI follows a linear trend, the spatial linear regression model is formulated by taking rainfall as an independent variable and NDVI as a regressed parameter. The regression analysis has been performed for each year from 2001 to 2011 after computing the slope and intercept for each pixel, in order to yield the result of a longer term NDVI that should have been present in the study region with respect to rainfall; hence it is called NDVI predicted. .

\subsection{Spatial correlation coefficient model}

In order to identify the negatively correlated area where the vegetation stress is dependent on wind speed, the spatial correlation coefficient analyses is done for a longer term mean wind speed and mean predicted NDVI (NDVI predicted $_{\text {) }}$ (Fig. 6b). Since the western part of the region is located on the leeward side, the land degradation process is significantly influenced by the prevalence of wind and high temperature events. Thus, the correlation coefficient analysis is again performed between temperature and wind speed $\left(R^{2}=0.83\right)$ in the negatively correlated zones of the wind speed-NDVI combination. This step is required in order to extract the combined effect (temperature- and wind-affected) zones of land degradation and desertification.

The region of positive correlation (wind speed$\left.\mathrm{NDVI}_{\text {predicted }}\right)$ is an indication of the condition where the vegetation has been resisted even after experiencing a high evaporation rate due to the occurrence of adequate rainfall. The spatial correlation coefficient analysis was again performed between Rainfall ${ }_{\text {mean }}$ and $\mathrm{NDVI}_{\text {predicted }}$ on the positively correlated area of wind speed-NDVI $\mathrm{N}_{\text {predicted }}$ which resulted in places of positive, negative and no correlation. Positive correlation indicates the $\mathrm{NDVI}_{\text {predicted }}$ of this region is well correlated with rainfall. If some degradation

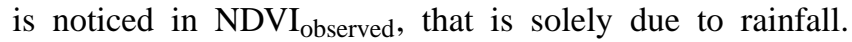
Degradation occurring in negatively correlated places (NDVI ${ }_{\text {predicted }}$ with rainfall) is the indication of human activities.

\subsection{NDVI $_{\text {normalized }}$ trend analysis}

A statistically significant negative slope in the NDVI time series is an indicator of degradation (Wessels et al., 2007). The long-term vegetation stress can be well identified and monitored by NDVI data and thus used for desertification assessment (Kundu and Dutta, 2011). The time trend analy- sis has been performed for a longer term NDVI to identify the spatiotemporal gradual and sudden changes in the vegetation condition of the study region over a period of time. Both a longer term (2001-2011) (Fig. 6a) and a short-term (2012-2015) trend have been estimated spatially for maximum NDVI.

\subsection{LULC (land use and land cover mapping) (2001, 2005, 2010 and 2014)}

At a regional level, both supervised and unsupervised classification works well for extracting soil salinity (Naseri, 1998). Supervised classification was performed for Landsat Satellite images of 2001, 2005, 2010 and 2014 in order to classify the saline, non-saline soils, wetlands and human structures. Maximum likelihood algorithm has been implemented in the supervised classification. About 50 in situ observations are used as samples for training the system to classify the images. The Level 1 land cover types, namely, forest region, agricultural land, wetland, built-up, barren land and water body were identified in the study region with the help of ground knowledge. The overall accuracy of the work was verified through confusion matrix, and the attained accuracy of the classification was $91 \%$.

\subsection{Diagonal Soil Moisture Stress Index (DSMSI)}

Few authors like Moren et al. (1994), Sandholt et al. (2002) and Shafian and Mass (2015) have proved the potential of the triangle and trapezoidal model on temperature-vegetation scatter plot in the extraction of soil moisture with adequate accuracy level $\left(R^{2}=0.703\right)$. The study region probably faced soil moisture stress due to low rainfall distribution, high wind speed and extreme temperature events during the crop-growing period from 2006 to 2011. Based on the pattern of the scatter plot of NDVI and TIR (thermal IR) band (Fig. 3a), we proposed the new empirical model called DSMSI with the association of wind speed to increase the accuracy and reliability of the soil moisture stress.

The distribution pattern of NDVI with respect to the TIR band follows a shape of an inclined rectangle. From the rectangle we found two wet edges and two dry edges based on their position on the scatter plot. Edge 1 and 2 are wet edges; 3 and 4 are dry edges. The diagonal line is formed from edge 1 to 4 , as edge 1 is extremely wet compared to edge 2 , and 4 is extremely dry compared to edge 3 . The wetness or moisture decreases with increasing diagonal distance (Eq. 1) from extreme wet edge 1.

Diagonal Distance $=\mathrm{TIR}_{i}+\left(\mathrm{ndvi}_{\max }-\mathrm{ndvi}_{i}\right) \sqrt{2}$

The diagonal distance has an inverse relationship with NDVI and direct correlation with wind speed. As shown in Fig. 3b the perpendicular line (a) erected from extreme wet (edge 1) to the line of edges 2-4. The pixels located at the left side of the line denote healthy vegetation because of the high NDVI 

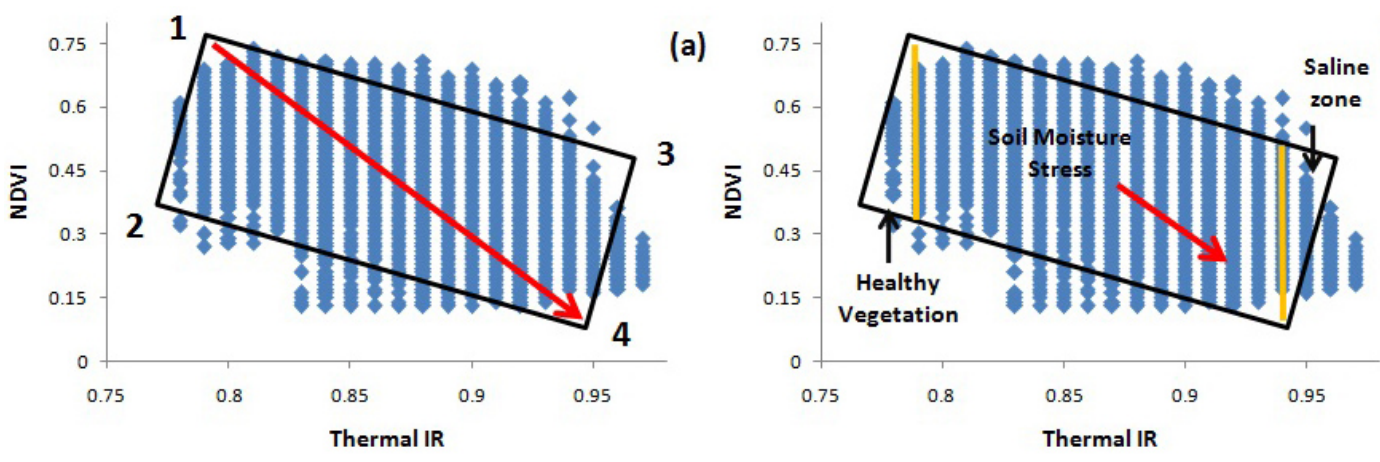

(b)
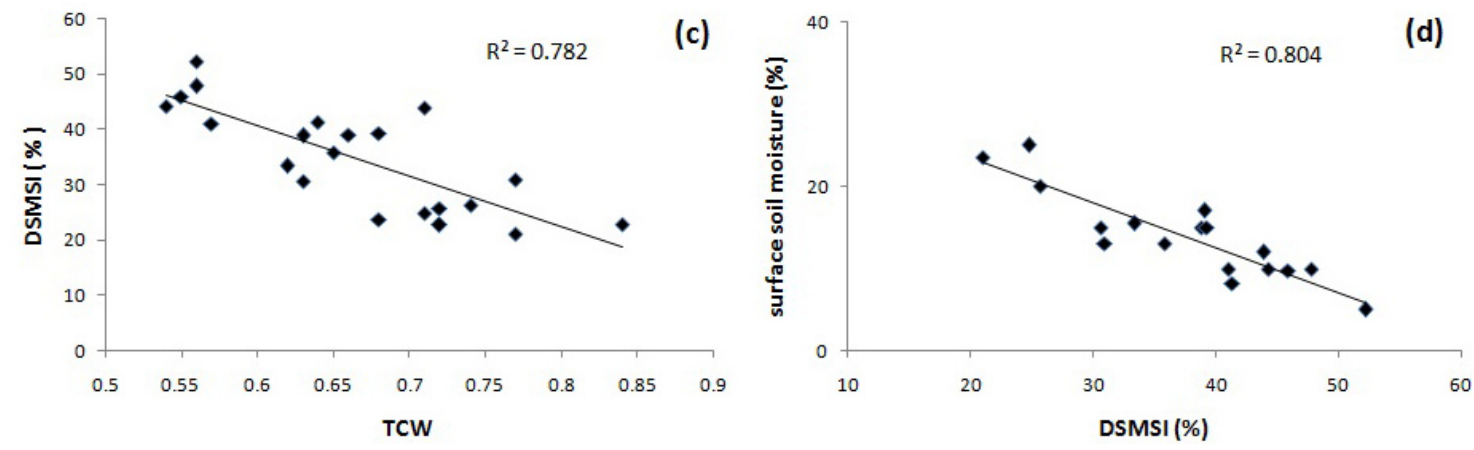

Figure 3. (a) Scatter plot - Thermal IR Vs NDVI - Diagrammatic approximation of the distribution - Diagonal from extreme wet edge 1 to extreme dry edge 4. (b) Three zones of scatter plot such as healthy zone with maximum NDVI and low temperature, soil moisture stress zone which keeps on increasing with increasing diagonal distance from wet edge and saline zone at the extreme portion of the rectangle where the temperature is high and NDVI is almost zero. (c) Linear regression between Diagonal Soil Moisture Stress Index (DSMSI) and Tasseled Cap wetness index (TCW) $\left(R^{2}=0.782\right)$ to ensure the theoretical reliability of the result. (d) Linear regression between DSMSI and in situ observations agrees with good accuracy $\left(R^{2}=0.804\right)$ of the model.

value and low temperature. Similarly, the perpendicular line (b) is again erected from the extremely dry edge 4 to the line of edges $1-3$. The pixels located on the right side of the line are extremely dry, thus termed as saline-affected soils. The pixels located in between the line a and $b$, depict the level of soil moisture stress. Hence, the scatter zone has been divided into three parts, namely healthy vegetation (zone 1), soil moisture stress (zone 2) and saline zone with moisture stress (zone 3). Therefore, there is strong convergence between soil moisture stress and salinity in the extreme diagonal zone. To reduce the misinterpretation between zone 2 and 3 and to increase the veracity of the DSMSI model in terms of soil moisture stress, the extreme portions of the resultant values are avoided and the most influential parameter of moisture stress, wind speed, was included in the equation.

Like temperature, the wind speed also influences the moisture content in the surface soil, which is not considered in the previous studies. Since the diagonal distance or moisture stress is inversely proportional to NDVI and directly proportional to wind speed, the model has been formed as shown in Eq. (2). TIR band and average wind speed data of the growing period were normalized before feeding them into the equation. Soil moisture stress maps of 4 years $(2001,2005$, 2010 and 2014) have been mapped using the DSMSI model
(Eq. 2). The DSMSI model is a function of NDVI, TIR and Wind speed.

$$
\begin{aligned}
\text { DSMSI } & =\left[\left(\frac{\left(\mathrm{TIR}_{i}+\left(\mathrm{ndvi}_{\max }-\mathrm{ndvi}_{i}\right)\right) \sqrt{2}}{\left(1+\mathrm{ndvi}_{i}\right)} \times 0.5\right)\right. \\
& \left.+\left(\mathrm{ws}_{i-\mathrm{norm}} \times 0.5\right)\right] \times 100,
\end{aligned}
$$

where DSMSI is the Diagonal Soil Moisture Stress Index (\%), $\mathrm{TIR}_{i}$ is the $i$ th pixel of normalized TIR band, ndvi $\mathrm{max}_{\max }$ is the maximum value of NDVI, ndvi $i_{i}$ is the $i$ th pixel of NDVI and $\mathrm{ws}_{i-\text { norm }}$ is the $i$ th pixel of normalized wind speed $\left(\mathrm{m} \mathrm{s}^{-1}\right)$.

The values of the model vary from 0 to 100 in which 0 indicates sufficient moisture content in the soil, 100 indicates the extreme dryness and intermediate values illustrates the moisture stress severity levels. Soil is said to be stressaffected if DSMSI $\geqq 60 \%$. DSMSI model has been regressed with $\mathrm{TCW}_{\mathrm{ETM}}+$ (Tasseled Cap wetness index) (Guo et al., 2011) in order to initially assess the theoretical reliability of the result; it yielded a best fit with TCW $\left(R^{2}=0.782\right)$ (Fig. 3c). 

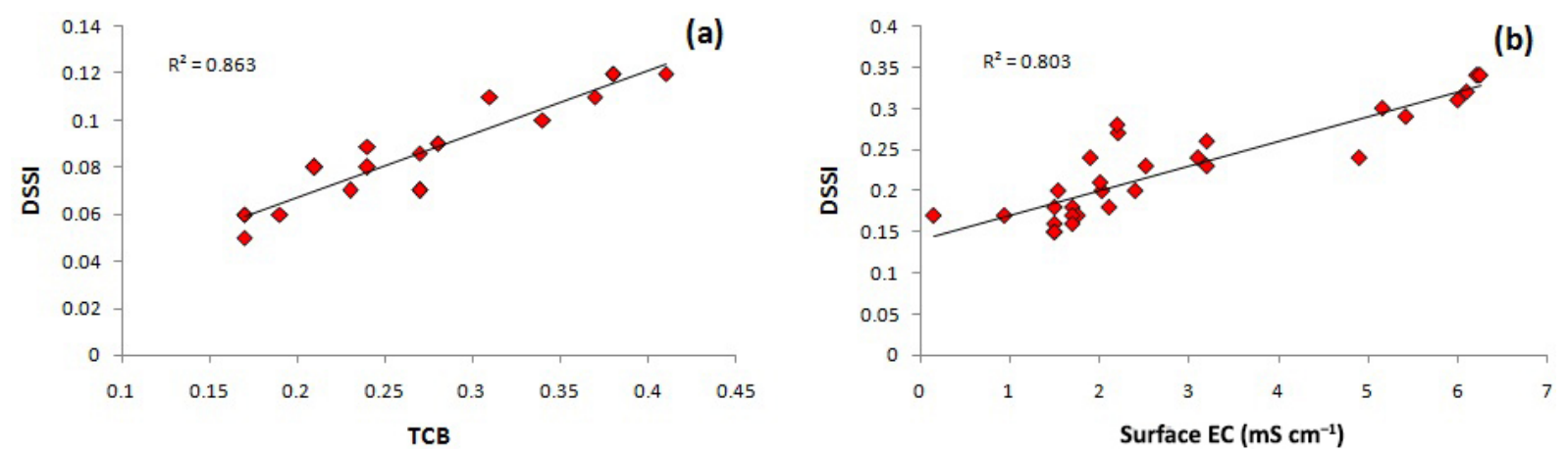

Figure 4. (a) The Diagonal Soil Salinity Index (DSSI) model confirms theoretical accuracy with Tasseled Cap brightness index (TCB) $\left(R^{2}=0.863\right)$. (b) The linear regression between DSSI and surface electrical conductivity (EC) $\left(R^{2}=0.803\right)$ which ensures the ground reliability of the model.

\subsection{Extraction of saline-affected soil}

Saline soils are very difficult to identify because of their dynamic nature. Dry areas are naturally prone to soil salinization due to a lower rate of rainfall and high evaporation which limits the leaching of salts, and this effect is expected to be magnified when it is combined with humans' negative intrusion like the over-fertilization of farmland (Metternicht and Zinck, 2009). Allbed et al. (2014) found that the Salinity Index (SI) and red band (band 3) have significant correlation with electrical conductivity (EC). Though much research has been carried out in the field of soil salinity identification so far, through various models like SI, Normalized Differential Salinity Index (NDSI) etc., an extraction of soil salinity still needs more accuracy because of the confusion created from the same spectral signature values of settlement roofs and saline-affected zones in the study region. Therefore, additional independent variables have to be involved in the analysis in order to reduce the places of uncertainty. Abdul-Qadir and Benni (2010) found that the mid-infrared (mid-IR) band has shown high correlation between SI and NDSI. Saline soils make it difficult for the plant to absorb the moisture content present in the soil, which results in soil moisture stress, especially at the root zone. Therefore, zone 3 (salinity-induced moisture stress) (Fig. 3b) in the present study is solely considered as saline-affected.

Since the diagonal distance of the scatter plot (Fig. 3a) had a similar relationship with soil salinity as the salinity increases with increasing diagonal distance, the same model was used in association with the mid-IR band for deriving a new model, named the Diagonal Soil Salinity Index (DSSI), which has increased the accuracy of extracting surface soil salinity with moisture stress at the extreme ranges. Inclusion of the mid-IR band in the model has significantly reduced the effect of building roofs on extracting salinity.

Spectral plot of the study region shows that the salineaffected region can be separated from the settlements from the 0.7 to 1 (after normalization) range in the mid-IR region.
Low organic matter exhibits higher reflectance in the midIR region rather than the settlements. The diagonal distance of the right-angled triangle, observed from the extreme corner of the scatter plot of mid-IR and NDVI, was considered as a saline line where the salinity increases with increasing distance from an apex point $(\mathrm{NDVI}=0.5$ and $\operatorname{mid}-\mathrm{IR}=0.7$ ). The negative values of the model were eliminated in the analysis, as the saline-affected regions maintain the range above 0.7 in the mid-IR region and below 0.5 in NDVI.

$\mathrm{DSSI}=\left[\frac{\left(\mathrm{TIR}_{i}+\left(\mathrm{ndvi}_{\max }-\mathrm{ndvi}_{i}\right)\right)}{\left(\left(\mathrm{MIR}_{i}-0.7\right)+\left(0.5-\mathrm{ndvi}_{i}\right)\right)}\right]$

Since the study region is expected to experience soil salinity because of the fluoride origin and extreme temperature event, surface level soil salinity was derived for the years 2001, 2005, 2010 and 2014 using the DSSI model (Eq. 3) as it yielded a best fit with TCB (Tasseled Cap brightness index) $\left(R^{2}=0.86\right)($ Fig. 4a).

\subsection{Testable directional hypothesis}

The directional hypothesis was formed in such a way that proves the expected direction of relationship between temperature-salinization, wind-soil moisture stress and rainfall-moisture stress at $0.05 \%$ confidence level. Based on the hypothesis, the rejection area, i.e., the area of high correlation existence between the variables, has been extracted for each case and shown in Table 1. For the temperature-salinity combination, the computed value of the $t$ statistic $(t=4.645)$ is higher than the tabulated one $(t=$ $3.482)$ at the 0.05 level of confidence, and this statement confirms the adequacy of the positive correlation between salinity and temperature. As anticipated, the salinity is a predominant degradation process in temperature/drought-affected zone. Likewise, other combinations have also proven its adequacy for higher correlation. The rainfall-moisture stress combination $t$ values $(-3.248)$ fell in the negative region of the histogram as the moisture stress is negatively correlated with rainfall. 
Table 1. Hypothesis combinations, computed $t$ values with $1 \%$ level of significance, corresponding probability ( $p$ score) and decision taken based on the tabulated values.

\begin{tabular}{llrrrl}
\hline Serial no. & Hypothesis variables & $p$ value & $\begin{array}{r}\text { Degrees of } \\
\text { freedom }\end{array}$ & $t$ value & Decision \\
\hline 1 & Temperature-salinity & 0.004 & $\mathrm{n}-2$ & 4.645 & $\begin{array}{l}\text { High } \\
\text { significance }\end{array}$ \\
2 & $\begin{array}{l}\text { Wind speed-moisture } \\
\text { stress }\end{array}$ & 0.005 & $\mathrm{n}-2$ & 3.576 & $\begin{array}{l}\text { High } \\
\text { significance }\end{array}$ \\
3 & $\begin{array}{l}\text { Rainfall-moisture } \\
\text { presence }\end{array}$ & 0.005 & $\mathrm{n}-2$ & -3.248 & $\begin{array}{l}\text { High } \\
\text { significance }\end{array}$ \\
\hline
\end{tabular}

\subsection{In situ observations}

In situ measurements are taken (Fig. 5b) for the chemical characteristics of the soil such as soil salinity, EC, $\mathrm{pH}$, temperature and soil moisture at 100 locations in and around the study region using EI Deep Vision water and soil analysis equipment (Model 161). A questionnaire was also conducted with the inhabitants of the study region, along with the field measurements, in order to be familiarized with the socioeconomic condition of the people, their land management practices and their awareness towards land degradation processes. Soil samples were collected at both surface and subsurface level $(1 \mathrm{~m})$ (Fig. 5f) and dissolved with groundwater of that region in order to facilitate the process of measuring chemical parameters as listed in Table 2.

Oleander (Nerium Oleander L.) is the only shrub planted in this affected region so as to withstand salinity. With this information, we discriminated salinity even under the vegetation while classifying Landsat images. Facts observed during the survey include the point that due to the migration of native people for their economic needs, the land was left abandoned for years on end which kept increasing the salinity with the absence of land management practices. In addition to that, farmers keep spending money on land reclamation, more than what they can get in return from the land, without knowing the actual condition/productivity of the land. In the dry areas, drip irrigation is practiced to achieve the needs of the growing population at times of insufficient rainfall. $\mathrm{Hu}-$ man activities such as real estate and urbanization more generally has started intruding the agricultural land which substantially affects the productive ecosystem.

\section{Results and discussion}

\subsection{Wind-temperature-induced degradation}

From the spatial correlation analysis between a longer term mean wind speed and mean predicted NDVI (Fig. 6b), we found that $46 \%$ (192395 ha) of land is negatively correlated, $48 \%$ (199526 ha) of land is positively correlated and $6 \%$ (21846 ha) is experiencing no correlation because of the stable NDVI over a period of time. The negatively

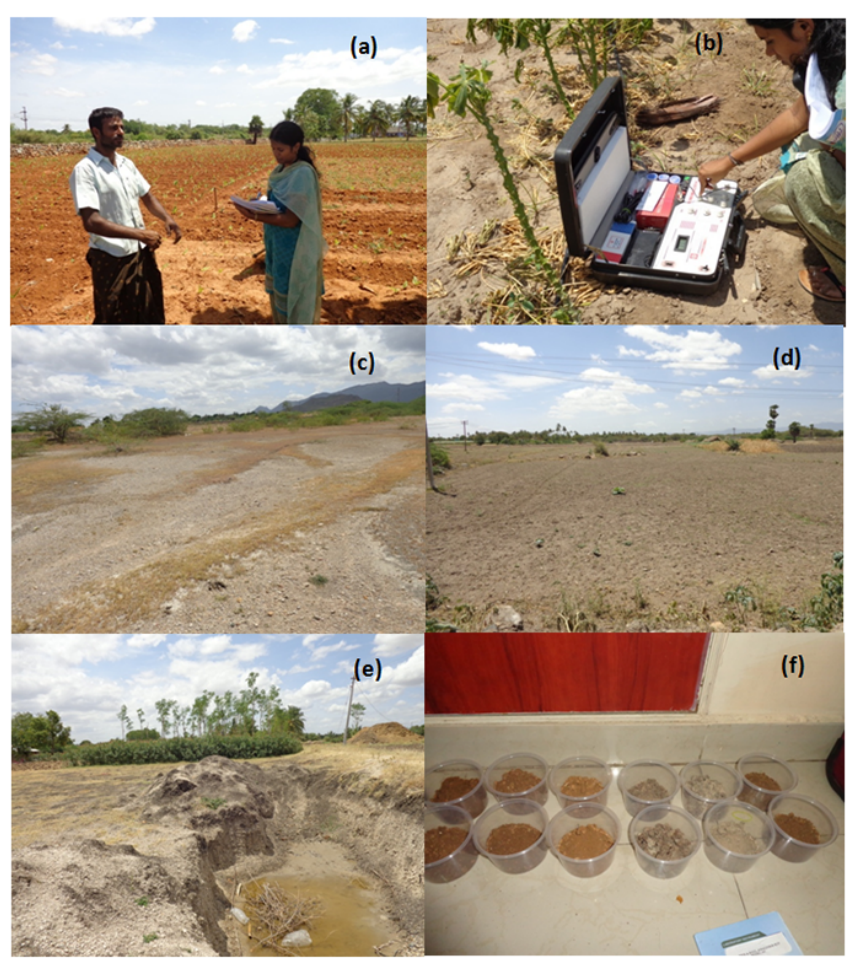

Figure 5. (a) Questionnaire with a local farmer. (b) Direct in situ measurement to evaluate the chemical properties of the soil. (c) Highly saline-affected region. (d) Soil moisture stress zone. (e) Land reclamation process hampered by the presence of hard pans. (f) Soil samples collected for testing the chemical properties.

correlated area is the direct illustration of NDVI reduction due to the high wind speed over a period of time. The land degradation due to wind speed is identified if the negative $\mathrm{NDVI}_{\text {observed }}$ trend (Fig. 6a) is observed in the negatively correlated area. The high correlation coefficient $\left(R^{2}=0.83\right)$ is observed between wind speed and temperature in the wind-induced degraded regions; hence the zone is termed as wind-temperature-induced degraded zone. Therefore, the temperature- and wind-induced degraded area has been identified from the analysis. Among 192395 ha, $26 \%$ (51 252.93 ha) of land parcel was affected by wind. 
Table 2. Statistical measure of the chemical parameters at sampled locations (33 per region). EC and salinity follow positive correlation with $\mathrm{pH}$ in the alkaline range (>7). The moisture content is below $35 \%$ in all three zones of desertification. In the drought-affected region the higher salinity is found at the subsurface level because of the fluoride concentration in groundwater. We found that the inverse relationship in human-induced desertified zone, i.e., the surface salinity, is higher than the subsurface and the standard deviation (SD) of surface-level salinity is lesser than the subsurface, which indicates that the human-induced salinity is not fluctuating at surface level because of the constant application of fertilizers for more than 2 decades. A high extent of surface-level soil moisture stress $(90 \%)$ is observed in the wind-induced desertified regions.

\begin{tabular}{|c|c|c|c|c|c|c|c|c|c|c|c|c|}
\hline \multirow[t]{3}{*}{ Chemical properties } & \multicolumn{4}{|c|}{$\begin{array}{l}\text { Rainfall-temperature/ } \\
\text { drought-induced } \\
\text { desertified region }\end{array}$} & \multicolumn{4}{|c|}{$\begin{array}{l}\text { Human-induced } \\
\text { desertified region }\end{array}$} & \multicolumn{4}{|c|}{$\begin{array}{l}\text { Wind-induced } \\
\text { desertified region }\end{array}$} \\
\hline & \multicolumn{2}{|c|}{$\begin{array}{l}\text { Surface } \\
\text { level }\end{array}$} & \multicolumn{2}{|c|}{$\begin{array}{l}\text { Subsurface } \\
\text { level }\end{array}$} & \multicolumn{2}{|c|}{$\begin{array}{c}\text { Surface } \\
\text { level }\end{array}$} & \multicolumn{2}{|c|}{$\begin{array}{c}\text { Subsurface } \\
\text { level }\end{array}$} & \multicolumn{2}{|c|}{$\begin{array}{c}\text { Surface } \\
\text { level }\end{array}$} & \multicolumn{2}{|c|}{$\begin{array}{c}\text { Subsurface } \\
\text { level }\end{array}$} \\
\hline & Mean & SD & Mean & SD & Mean & SD & Mean & SD & Mean & SD & Mean & SD \\
\hline $\mathrm{pH}$ & 7.90 & 0.9 & 8.10 & 0.40 & 8.80 & 0.28 & 7.74 & 1.10 & 7.00 & 1.49 & 7.46 & 0.72 \\
\hline $\begin{array}{l}\mathrm{EC} \\
\left(\mathrm{mS} \mathrm{cm}^{-1}\right)\end{array}$ & 3.73 & 1.1 & 4.65 & 0.43 & 5.10 & 0.85 & 4.4 & 1.46 & 2.05 & 1.6 & 3.12 & 0.7 \\
\hline $\begin{array}{l}\text { Salinity } \\
\text { (ppt) }\end{array}$ & 3 & 1.5 & 4.2 & 0.50 & 4.35 & 0.93 & 3.15 & 1.49 & 1.90 & 1.44 & 3.10 & 0.95 \\
\hline $\begin{array}{l}\text { Soil } \\
\text { moisture } \\
(\%)\end{array}$ & 19 & 1.53 & 30.0 & 1.02 & 20.0 & 1.26 & 32.0 & 1.10 & 15.0 & 1.34 & 31.0 & 1.00 \\
\hline
\end{tabular}

\subsection{Rainfall-temperature/drought and human-induced degradation}

The positively correlated area of wind speed $_{\text {mean }}$ and $\mathrm{NDVI}_{\text {pred }}$ indicates the consistency of the vegetation even after experiencing high wind speed due to the steady rate of rainfall over a period of time. Therefore if the degradation is suspected to occur in this region, it is mainly due to rainfall and temperature or human factors. Rainfall and temperature/drought-induced degradation was identified if the negative $\mathrm{NDVI}_{\text {observed }}$ trend is observed in the positively correlated area of rainfall and $\mathrm{NDVI}_{\text {pred }}$.

Similarly, human-induced degradation was identified if the negative $\mathrm{NDVI}_{\text {observed }}$ trend is observed in the negatively correlated area. The human-induced degradation cannot be directly acquired from the geostatistical model because of its dynamic nature. Once the possible climatic degradations (wind, rainfall and temperature) were extracted from the correlation analysis, the remaining area (positive correlation between wind speed and $\mathrm{NDVI}_{\text {pred }}$; negative correlation between rainfall and $\mathrm{NDVI}_{\text {pred }}$ with decreasing NDVI trend) is identified as being human-affected. The vegetal status of this region is low because of the human intrusion. Among 199526 ha, 46\% (93 138.12 ha) are affected by insufficient rainfall and extreme temperature event and $21 \%$ (42 184.26 ha) are affected by human intrusion. Figure 6c depicts the degraded zones with respect to wind-temperature, rainfall-temperature/drought and human factors.

\subsection{Land degradation to desertification}

As discussed earlier, in this study, if the degraded land is not responding well to the sufficient rainfall, then the situation is termed as desertification. Desertified land area is identified by considering the short-term NDVI (2012-2015) trend when the rainfall rate is sufficient for the plant growth. Desertified area has been extracted where the degraded land is still facing a negative short-term NDVI trend. About $70 \%$ (121 179.15 ha) of the degraded land would have been wrongly identified as desertified land if the short-term NDVI trend had not been included in the analysis. The research found that $15 \%$ of the total area (439 189.71 ha) is in a desertified state. Figure $6 \mathrm{~d}$ illustrates the three zones of desertification due to wind-temperature, rainfall-temperature and human events.

\subsection{Soil degradation process induced by wind-temperature, rainfall-temperature/drought and human intrusion}

The soil degradation process, invoked by the four crucial factors, is recognized in the present study as soil is the predominant component which becomes deteriorated by the process. Red gravelly clay soil is predominately found in the droughtaffected region. The fine pores of clay-like soil have a great ability to retain the water through capillary action. Therefore, the soil of the drought-affected region has naturally inherited high fluoride content from the groundwater through capillary action. During times of extreme temperatures, the saline water in the subsurface and some surface levels of the soil evap- 


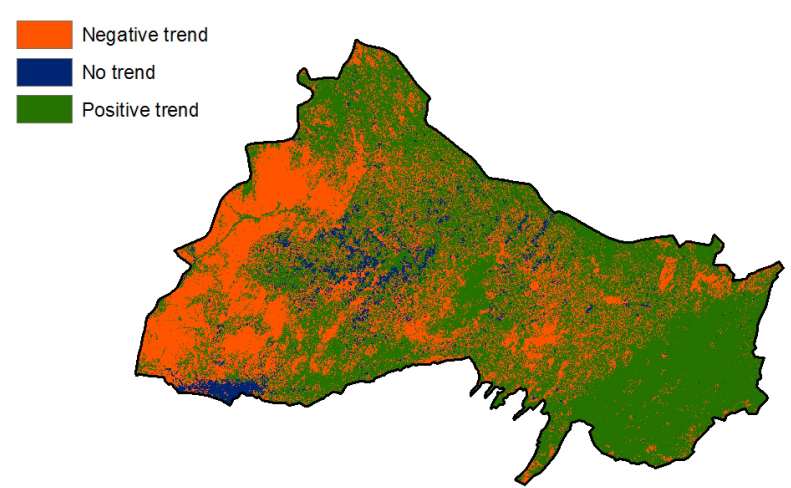

(a)

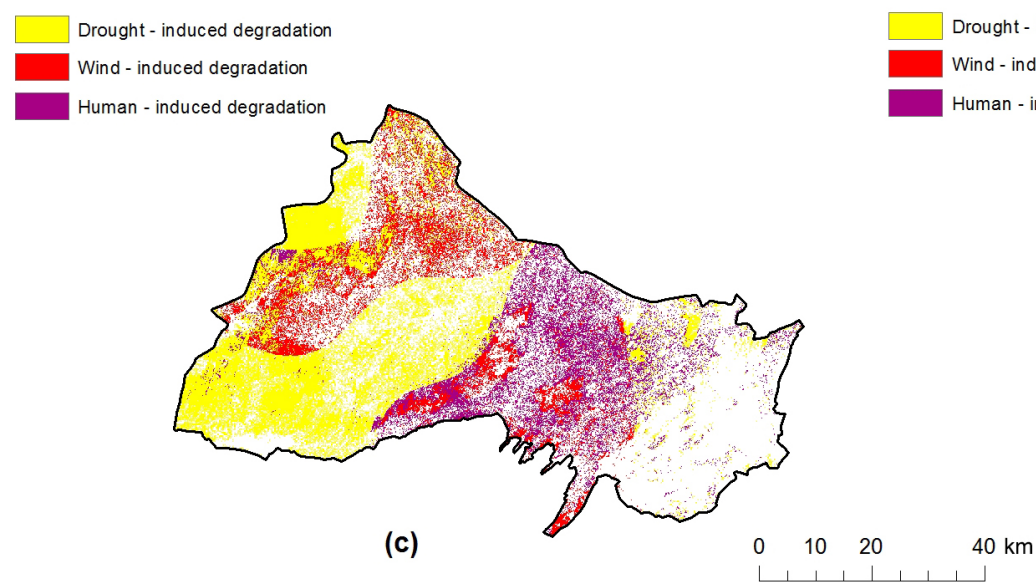

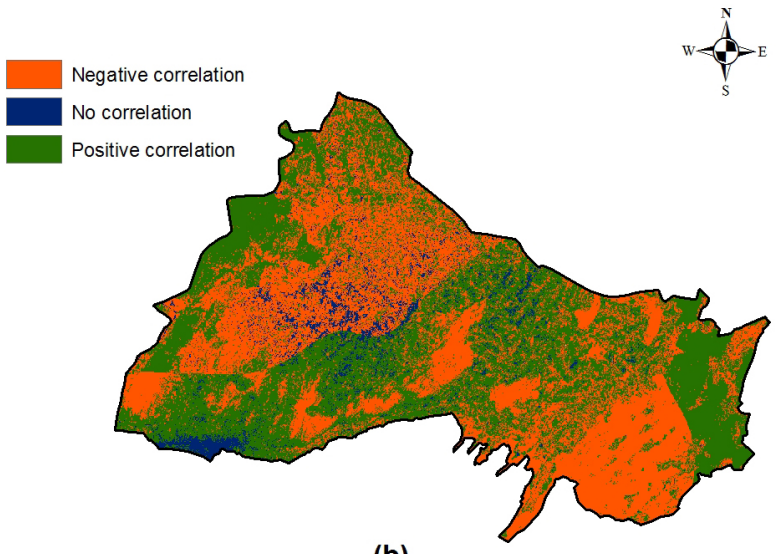

(b)
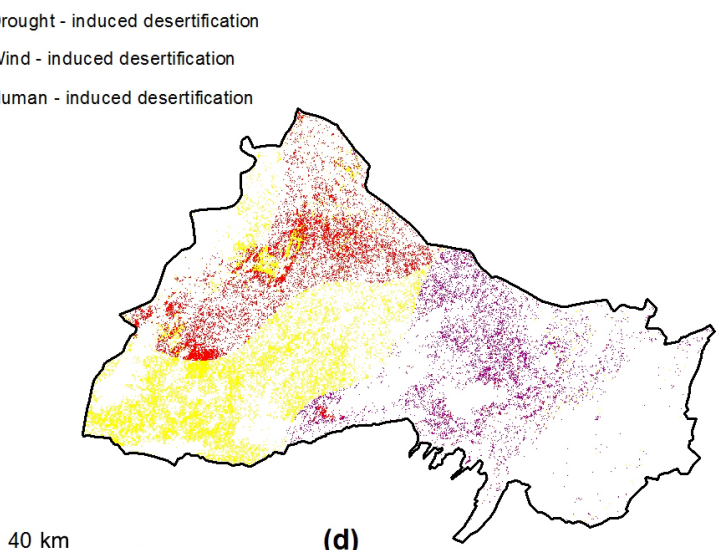

Figure 6. (a) Long-term mean $\mathrm{NDVI}_{\mathrm{observed}}$ trend. Area of no correlation in (b) is exactly coincided with no change area (a) i.e this is the place of no correlation between wind speed and NDVI due to the presence of stable/undisturbed NDVI over a period of time. (b) Correlation coefficient map for wind speed mean $_{\text {and NDVI }}$ predicted mean for 11 years. Eastern (low wind speed and high NDVI) and western parts (High wind speed and low NDVI) of the study region have been experiencing high negative correlation over a period of time. (c) Distribution of degraded land with respect to three crucial causative factors, namely drought, wind and human. (d) Distribution of desertified land extracted from degraded zones after the assessment with the short-term NDVI $I_{\text {observed }}$ trend (2012-2015). Western areas of the region display combined effects of drought and wind. Though the eastern part receives adequate rain and experiences moderate temperature and wind, which is appropriate for vegetation production, the distribution of desertified land is higher due to anthropogenic activities.

orates and salt remains accumulated, as cited earlier. Higher fluoride content and extreme $\mathrm{pH}$ have high positive correlation and thus enable the water and soil to experience salinity (Adhikary et al., 2014b).

In the drought-affected zone the soil salinity should have been accelerated due to native fluoride concentration on groundwater, a high evaporation rate induced by temperature and the absence of the leaching process because of the inadequate amount of rainfall over a period of time. As hypothesized, the drought-induced desertified area should have been strongly affected by salinity. Higher salinity hinders the vegetation growth and thus supports the water erosion and saline leaching process during the occurrence of extreme rain soon after a longer period of insufficient rainfall, which happened in 2012. Surface-level soil salinity was estimated for 2001, 2005, 2010 and 2015 using the DSSI model as it yielded a best fit with ground truth measurements $\left(R^{2}=0.803\right)$ (Fig. $\left.4 \mathrm{~b}\right)$. The area of soil salinity has been significantly increased from 12 to $58 \%$ in the droughtaffected regions compared to the area of soil moisture stress ( 5 to $33 \%$ ) from 2001 to 2015 . The soil moisture stress has also been activated severely in surface and root zones (subsurface), especially in the 2006 to 2011 time frame, and this effect still had an elevated rate from 2012 to 2015 . Though the soil moisture stress is being steadily increased due to high temperature prevalence and rainfall insufficiency, the increment rate of surface salinity is exceeding at an unexpected rate over a period of time (Fig. 7a).

Hence, the initial prediction has proved that the droughtaffected zone should have emphatically experienced a higher 

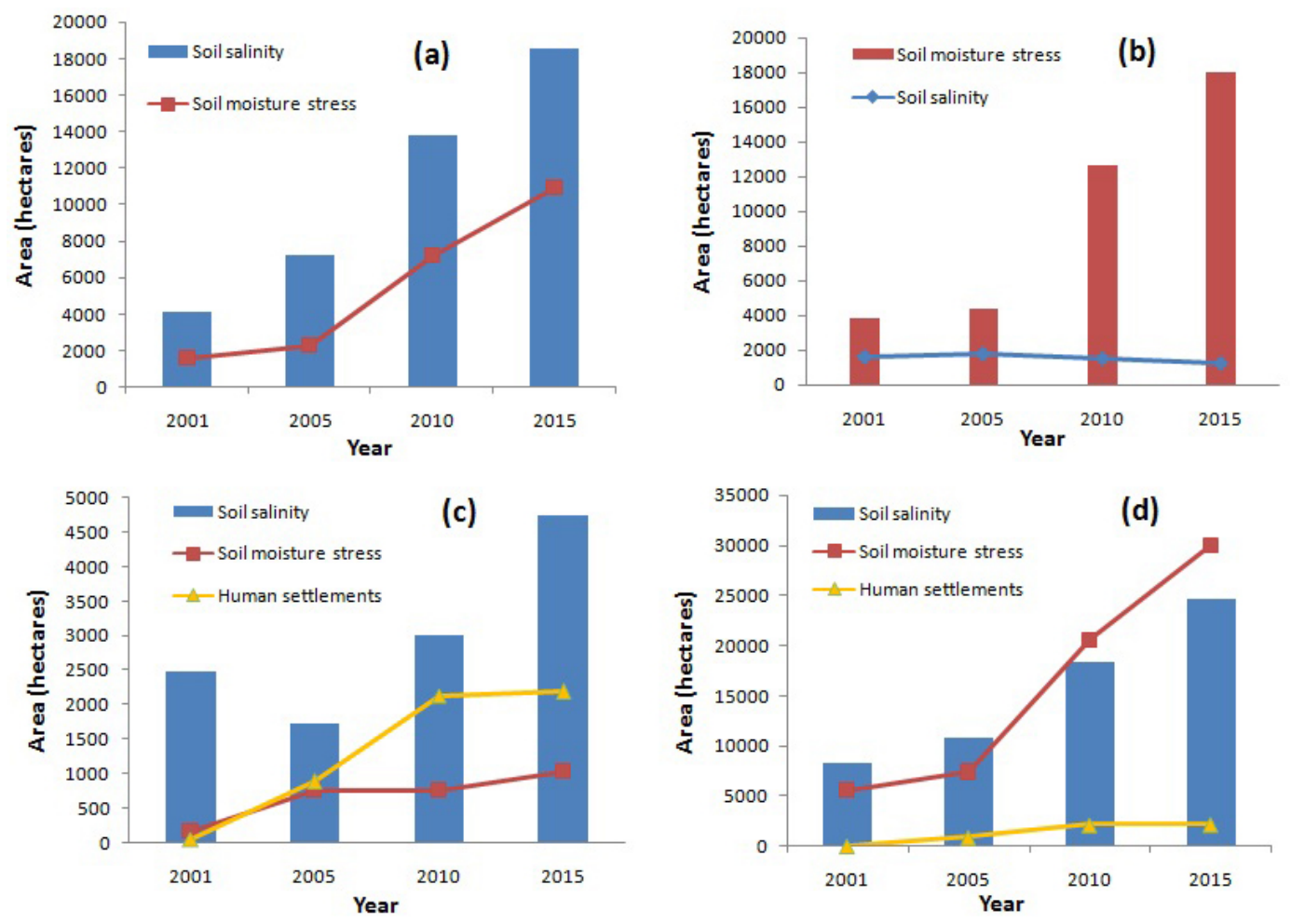

Figure 7. (a) Areal extent of soil moisture and soil salinity for drought-affected zone from 2001 to 2015 , in which the growth of salineaffected regions is in high proportion compared to the moisture-affected regions due to native fluoride content and clayey soil origin. (b) Areal extent of soil moisture and salinity in wind-affected zone from 2001 to 2015 . The soil moisture stress has been accelerated in the wind-affected zone, rather than the salinity. (c) Soil salinity, moisture stress and human occupancy are together observed in the human-affected region from 2001 to 2015 . Human settlements are elevated at a higher rate, followed by man-made salinity and soil moisture stress. (d) The overall rate of soil degradation processes at the study region irrespective of the causative factors.

level of soil salinity than other soil degradation factors. From the ground truth observations it was noticed that the subsurface salinity or EC was significantly higher (mean $6.5 \mathrm{mS} \mathrm{cm}^{-1}$ ) than the surface salinity (mean $4.2 \mathrm{mS} \mathrm{cm}^{-1}$ ) in the drought-affected zone. The distribution of salinity follows a continuous pattern in the drought- and wind-affected region (climate-influenced region). The low rainfall will decrease the decomposition rate in the soil, thereby reducing the nutrient content in the rainfall-affected regions. Therefore, nutrient losses are observed in this region along with soil moisture stress from in situ observations.

Based on the directional hypothesis, the windtemperature-affected region is expected to experience soil moisture stress at the surface level. Therefore, the further component, the surface soil moisture stress, was extracted for 2001, 2005, 2010 and 2015 through the DSMSI model, and it yielded a best fit with in situ observations $\left(R^{2}=0.804\right)$ (Fig. 3d). The area of surface soil moisture stress increased constantly (19 to $90 \%$ ) from 2001 to 2015 in the region where wind is the predominant inducing factor. Soil salinity in these regions fluctuated at a somewhat lower rate $(8 \%$ in $2001,9 \%$ in $2005,7 \%$ in 2010 and $6 \%$ in 2015 ) and that too is due to native fluoride content. During the degradation phase from 2006 to 2011, we found that a higher rate $(63 \%)$ of soil moisture stress had been caused by the wind (Fig. 7b). As hypothesized, the area of soil moisture stress (Fig. 7) in the wind-temperature-induced desertified region (18052 ha) is comparatively higher than the drought-induced (9161 ha) and human-induced (1042 ha) region.

Though the levels of moisture stress and salinity were obtained at surface level effectively in the drought- and windaffected region using the DSMSI and DSSI model, we could not model the subsurface moisture stress and salinity as we have dealt with multispectral images which do not have surface penetration capacity. The DSMSI model is only applicable for dry conditions/the leeward side of mountain regions where the occurrence of rainfall is majorly hampered by the augmentation of wind speed and temperature. Conversely, the model is not applicable to the areas where the (i) rate of urbanization is high; (ii) the soil is waterlogged in a higher proportion; (iii) there is an active presence of water bodies. Similarly, the DSSI model is also applicable for dry conditions and not suitable for waterlogging situations. Therefore, the model was only employed in climate-affected regions (drought- and wind-affected region). 
The consequences of the above two declared factors of desertification, namely drought and wind, are slow and can be suspected and quantified with respect to past, current and future prediction models as they solely depend on climatic variables. But the third factor, human activities, causes an adverse effect on the land in an unexpected and rapid manner and cannot be predicted in advance. According to Vieira et al. (2015) human activities are the predominant factor for desertification expansion. In the case of human-affected regions, the salinity was measured from LULC maps, not from the model, as the uncertainty developed from the distribution of Oleander (Nerium Oleander L.) plants on the saline track (mentioned in Sect. 2.13) and waterlogging condition. The human-induced desertified regions were affected by salinity, human occupancy followed by moisture stress (Fig. 7d).

Human-induced salinity increased by $9 \%$ in the degradation phase and becomes accelerated in the desertification phase $(14 \%)$. About $5 \%$ of the saline track increased in the desertification phase. Dissolved nitrate is the main source for the concentration of fluoride in the groundwater. There is no evidence for the geological source of nitrate (Ramesh and Vennila, 2012) in the human-induced desertified region. Therefore, it was resultant from human activities. The surface EC values are higher than the subsurface in the humanaffected region. The fact may be supported by the opinions obtained by local farmers (Fig. 5a) that the long-term application of fertilizers for more than 2 decades raises the salinity in the soil more than the fluoride does. In the human-affected regions, extreme surface salinity is observed in few low-lying areas (Fig. 5c), because of the leaching of fertilizers from surrounding elevated areas. The distribution of salinity is discrete in the human-affected regions. Hence, the substantial increment of salinity in the human-affected zone was due to the high application of fertilizers on land that is already fragile to achieve a high production rate, more than its sustainable capacity in order to support the growing population.

Furthermore the human occupancy has significantly increased from 2001 to 2015 , particularly in the degradation period (2006-2011). This is due to the increment of population (8\%) from 2001 to 2011 (Fig. 8) in the human-affected region. Population growth of the other regions (temperature/drought affected, rainfall-affected and wind-affected) has followed a decreasing trend from 2001 to 2011, which is the direct illustration of migration of the inhabitants to urbanized areas due to the prevalence of drought in these years. About $38 \%$ of decadal growth (2001-2011) of the population was particularly observed in the urban areas of the study region (Census of India, 2011). Therefore, during the aridity stage, human pressure should have started on the agricultural land in order to support the growing population or attain financial security, as the agricultural practice was not very feasible in the period. Figure 7d depicts the rate of increment of salinity and urbanization. Soil moisture stress had little effect in the human-affected region, which only increases by $1 \%$ during the degradation phase.

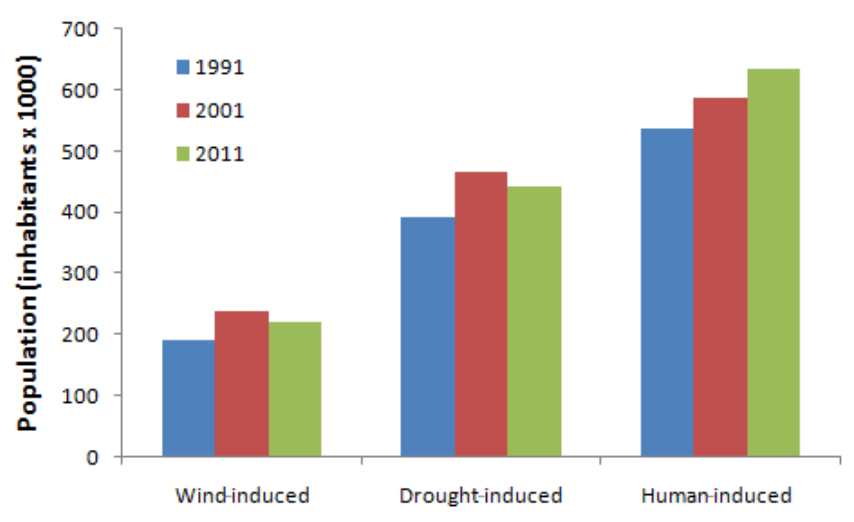

Figure 8. Population trend of three zones of desertification from 1991 to 2011 . The population trend has been significantly increased (8\%) from 2001 to 2011 in the human-induced desertified zone, where as in the temperature/drought, wind and rainfall-affected zone, it follows a decreasing trend. This is because of the migration of the inhabitants towards urbanized area in order to stabilize their economical needs during drought period.

The standard deviation of subsurface EC and salinity is significantly higher (1.46 and 1.49) than the surface level which shows that the values of the salinity are highly fluctuating at the subsurface level (Table 1) particularly in the human-affected zone. Hence, the DSSI model has yielded poor accuracy for the subsurface level $\left(R^{2}=0.5\right)$, particularly in the human-affected region. This is because of the leaching of salts due to the application of excess amount of fertilizers for more than 2 decades.

\section{Conclusions}

The proposed study focused on four driving forces such as temperature-, wind-, rainfall- and human-induced factors for the assessment of land degradation and desertification with the aid of an appropriate geostatistical model. The successful directional hypothesis has assisted the research in the identification of the highly influential soil degradation process in all three affected zones. From the new perspective of assessment, appropriate models can be applied to the area based on the predicted soil degradation process, because we cannot apply a soil erosion model to a region which has been affected by salinity over the years. However, some limitations are demonstrated in the present work which have to be improved upon in future research. (1) The wind-affected region would have also faced strong wind erosion, but only soil moisture stress was studied. (2) Either soil salinity or soil moisture is extracted at surface level only, but in the study area, the salinity has been inherited from the groundwater and it is expected to be present at the subsurface level too, which cannot be measured by multispectral remote sensing models. (3) A study of soil textural variations would increase the reliability of the results. (4) Human activities are stud- 
ied through LULC maps, but the incorporation of overgrazing and an excessive yield estimation model may increase the quality of the work. (5) Since soil salinity, soil moisture stress and hard pans are the dominant features present in the surface and subsurface levels, recent advanced technology like microwave remote sensing should be employed in order to quantify the salinity regions accurately. Because of the potentiality of all weathers, the capability of surface penetration and the response towards the electrical properties of the target, microwave remote sensing is able to provide adequate ground for extracting the surface and subsurface salinity and moisture compared to other methods such as optical and multispectral remote sensing.

Acknowledgements. We would like to express our sincere thanks to Department of Science and Technology, India, for the financial support (grant no. DST/Inspire Fellowship/2013/1109/IF131152), without which we would not have been able to purchase the required instruments and data to carry out the research work.

We thank the Centre for Climate Change and Adaptation Research, Anna University, for providing the meteorological data on time, and we are also thankful to the USGS for their free distribution of long-term Landsat images through the online data portal.

Edited by: A. Cerdà

\section{References}

Abdul-Qadir, A. M. H. and Benni, T. J.: Monitoring and evaluation of soil salinity in term of spectral response using Landsat images and GIS in Mesopotamian plain/Iraq, Journal of Iraqi Desert Studies, 2, 19-32, 2010.

Adhikary, P. P., Dash, C. J., Sarangi, A., and Singh, D. K.: Hydrochemical characterization and spatial distribution of fluoride in groundwater of Delhi state, India, Indian J. Soil Conserv., 42, 170-173, 2014.

Akhtar-Schuster, M., Thomas, R. J., Stringer, L. C., Chasek, P., and Seely, M.: Improving the enabling environment to combat land degradation: Institutional, financial, legal and science-policy challenges and solutions, Land Degrad. Dev., 22, 299-312, 2011.

Allbed, A., Kumar, L., and Sinha, P.: Mapping and Modelling Spatial Variation in Soil Salinity in the Al Hassa Oasis Based on Remote Sensing Indicators and Regression Techniques, Remote Sens., 6, 1137-1157, 2014.

Anbazhagan, S., Palpandian, P., Jothibasu, A., Uma Maheswaran, S., Venkatesan, A., and Ramesh, V.: GIS spatial analysis for artificial recharge - a case study from drought prone area, in: Water Management - Historical Perspective and Development, edited by: Anbazhagan, S., Vasagan Publication, ISBN: 978-93-8318801-7, 107-133, 2013.

Barbero-Sierra, C., Marques, M. J., Ruiz-Pérez, M., Escadafal, R., and Exbrayat, W.: How is Desertification Research Addressed in Spain? Land Versus Soil Approaches, Land Degrad. Dev., 26, 423-432, 2015.
Bisaro, A., Kirk, M., Zdruli, P., and Zimmermann, W.: Global Drivers setting Desertification research priorities: Insights from a stakeholder consultation forum, Land Degrad. Dev., 25, 5-16, 2014.

Census of India: Provisional population Totals - Rural and Urban Distribution, Paper 2, volume 1, series 34, office of the Registrar General \& Census Commissioner, India, Data Product No.00004-2011-Cen-Book(E), available at: http://censusindia.gov.in/ 2011-prov-results/paper2/prov_results_paper2_india.html (last access: 1 November 2015), 2011.

Central Ground Water Board: District Groundwater Brochure Dharmapuri District, Tamil Nadu, Technical Report Series, Ministry of Water Resources, Government of India, available at: http: //cgwb.gov.in/District_Profile/TamilNadu/Dharmapuri.pdf (last access: 5 February 2015), 2009.

D'Odorico, P., Bhattachan, A., Davis, K. F., Ravi, S., and Runyan, C. W.: Global desertification: Drivers and feedbacks, Adv. Water Resour., 51, 326-344, 2013.

Fleskens, L. and Stringer, L. C.: Land management and policy responses to mitigate desertification and land degradation, Land Degrad. Dev., 25, 1-4, 2014.

Guo, M., Liu, Y., Wang, X. F., Matsuoka, N., and Tani, H.: Analysis of Desertification and Wood Land Distribution: A Case Study on the Balinyou Banner of Inner Mongolia, China, International Society for Photogrammetry and Remote Sensing Proceedings, available at: http://www.isprs.org/proceedings/2011/ISRSE-34/ 211104015Final00042.pdf (last access: 13 June 2015), 2011.

Hanan, N. P., Prince, S. D., and Hiernaux, P. H. Y.: Spectral modeling of multi component landscapes in the Sahel, Int. J. Remote Sens., 12, 1243-1258, 1991.

Hill, J.: LADAMER: Land and Soil Degradation Assessments in Mediterranean Europe, available at: https: //www.uni-trier.de/fileadmin/fb6/prof/FER/Bilder-Forschung/ Ladamer/GMES-Paper_Nordwijk.pdf (last access: 3 September 2015), 2005.

Izzo, M., Araujo, N., Aucelli, P. P. C., Maratea, A., and Sánchez, A.: LAND sensitivity to desertification in the dominican republic: AN adaptation of the ESA methodology, Land Degrad. Dev., 24, 486-498, 2013.

Kassas, M.: Arid and Semi-arid Lands: Problems and Prospects, Agro-Ecosystem, Elsevier Scientific Publishing Company, Amstredam - Printed in the Netherlands, available at: http://kassas. org/wp-content/uploads/2013/03/026.pdf (last access: 7 April 2015), 3, 185-204, 1977.

Kundu, A. and Dutta, D.: Monitoring desertification risk through climate change and human interference using Remote sensing and GIS techniques, Int. J. Geomat. Geosci., 2, 21-33, 2011.

Lin, N.-F. and Tang, J.: Geological environment and causes for desertification in arid-semi-arid regions in China, Environ. Geol., 41, 806-815, 2002.

Low, P. S. (Ed.).: Economic and social impacts of desertification, land degradation and drought, White Paper I. UNCCD 2nd Scientific Conference, prepared with the contributions of an international group of scientists, available at: http://2sc.unccd.int/fileadmin/unccd/upload/documents/ WhitePapers/White_Paper_1.pdf (last access: 9 February 2016), 2013.

Metternicht, G. and Zinck, J. A. (Eds.): Remote Sensing of Soil Salinization: Impact on Land Management, Taylor and Francis 
Group, LCC, CRC Press: Boca Raton, FL, USA, ISBN 978-14200-6502-2, 2009.

Meyer, P., Itten, K. I., Kellenberger, T., Sandmeier, S., and Sandmeier, R.: Radiometric Corrections of Topographically Induced Effects on Landsat TM Data in an Alpine Environment, J. Photogramm. Remote Sens., 48, 17-28, 1993.

Miao, L., Moore, J. C., Zeng, F., Lei, J., Ding, J., He, B., and Cui, X.: Footprint of Research in Desertification Management in China, Land Degrad. Dev., 26, 450-457, 2015.

Moran, M. S., Clarke, T. R., Inoue, Y., and Vidal, A.: Estimating crop water deficit using the relation between surface-air temperature and spectral vegetation index, Remote Sens. Environ., 49, 246-263, 1994.

Naseri, M. Y.: Characterization of salt-affected soils for modeling sustainable land management in semi-arid environment; a case study in the Gorgan region, Northeast Iran, PhD Thesis, Ghent University, Belgium, 281-287, 1998.

Nicholson, S. E., Davenport, M. L., and Malo, A. R.: A comparison of the vegetation response to rainfall in the Sahel and East Africa using normalized difference vegetation index from NOAA AVHRR, Clim. Change, 17, 209-241, 1990.

Ramesh, K. and Soorya, V.: Fluoride Contamination in Drinking Water in Palacode Region, Tamil Nadu, Int. J. Res. Chem. Environ., 2, 116-123, 2012.

Rasmussen, K., Fog, B., and Madsen, J. E.: Desertification in reverse? Observations from northern Burkina Faso, Glob. Environ. Change, 11, 271-282, 2001.

Roxo, M. J., Casimiro, P., and Tiago, M. S.: What is Desertification, Desert Links project, Framework- European Union, Geografia e Planeamento Regional - Faculdade de Ciências Sociais e Humanas - Universidade Nova de Lisboa, available at: https://www.kcl.ac.uk/projects/desertlinks/downloads/ deliverables/Deliverable\%201.2b_en.pdf (last access: 2 February 2015), 2001.

Runnstrom, M. C.: Rangeland development of the Mu Us sandy land in semi-arid china: an analysis using landsat and NOAA remote sensing data, Land Degrad. Dev., 14, 189-202, 2003.

Salvati, L., Zitti, M., and Perini, L.: Fifty years on: Long-term patterns of land sensitivity to desertification in Italy, Land Degrad. Dev., doi:10.1002/ldr.2226, 2013.

Sandholt, I., Rasmussen, K., and Andersen, J.: A simple interpretation of the surface temperature/vegetation index space for assessment of soil moisture status, Remote Sens. Environ., 79, 213224, 2002.

Sendesh, K. K., Ramasubramanian, V., and Sathyaraj, S. R.: Identification of Fluoride contaminations with the interaction of physio-chemical characteristic in Groundwater of Dharmapuri District, TamilNadu, INDIA, Archives Appl. Sci. Res., 3, 336351, 2011.

Shafian, S. and Maas, S. J.: Index of Soil Moisture Using Raw Landsat Image Digital Count Data in Texas High Plains, Remote Sens., 7, 2352-2372, 2015.

Sharmia, S.: DESERTIFICATION - about drought, desertification and poverty in the drylands, Google Blog, available at: https://desertification.wordpress.com/2008/06/23/ excessive-irrigation-promotes-desertification-google-the-new-nation/ (last access: 3 June 2015), 2008.
Shewale, M. P. and Shravan, K.: Climatological features of Drought incidences in India, Meteorological Department Report, National climate centre, Office of the additional director general of meteorology (Research), India Meteorological Department, Pune, available at: http://www.imdpune.gov.in/research/ drought/DROUGHT_CLIMATOLOGY_1.pdf (last access: 13 June 2015), 2005.

Torres, L., Abraham, E. M., Rubio, C., Barbero-Sierra, C., and Ruiz-Pérez, M.: Desertification Research in Argentina, Land Degrad. Dev., 26, 433-440, 2015.

UNCCD: United Nations Convention to Combat Desertification, Geneva, Switzerland, United Nations, available at: https://www.kcl.ac.uk/projects/desertlinks/downloads/ deliverables/Deliverable\%201.2b_en.pdf (last access: 3 March 2015), 58 pp., 1994.

UNCCD: Zero Net Land Degradation - A Sustainable Development Goal for Rio +20, UNCCD Secretariat Recommendations for Policymakers, available at: http://www.unccd.int/Lists/SiteDocumentLibrary/Rio+20/ UNCCD_PolicyBrief_ZeroNetLandDegradation.pdf (last access: 3 March 2015), ISBN 978-92-95043-62-6, 2012.

Soil Survey Staff: US Deptartment of Agriculture: Keys to Soil Taxonomy, 12th Edn., USDA-Natural Resources Conservation Service, Washington, DC, 372 pp., 2014.

Vieira, R. M. S. P., Tomasella, J., Alvalá, R. C. S., Sestini, M. F., Affonso, A. G., Rodriguez, D. A., Barbosa, A. A., Cunha, A. P. M. A., Valles, G. F., Crepani, E., de Oliveira, S. B. P., de Souza, M. S. B., Calil, P. M., de Carvalho, M. A., Valeriano, D. M., Campello, F. C. B., and Santana, M. O.: Identifying areas susceptible to desertification in the Brazilian northeast, Solid Earth, 6, 347-360, doi:10.5194/se-6-347-2015, 2015.

Wang, T., Xue, X., Zhou, L., and Guo, J.: Combating Aeolian Desertification in Northern China, Land Degrad. Dev., 26, 118-132, 2015.

Wang, X., Chen, F., and Dong, Z.: The relative role of climatic and human factors in desertification in semi-arid China, Glob. Environ. Change, 16, 48-57, 2006.

Wang, X. M., Zhang, C. X., Hasi, E., and Dong, Z. B.: Has the Three Norths Forest Shelterbelt Program solved the desertification and dust storm problems in arid and semiarid China, J. Arid Environ., 74, 13-22, 2010.

Wessels, K. J., Prince, A. S., Carroll, M., and Malherbe, J.: Relevance of rangeland degradation in semi-arid north eastern South Africa to the non-equilibrium theory, Ecol. Appl., 17, 815-827, 2007.

Williams, D. L., Goward, S., and Arvidson, T.: Landsat: yesterday, today, and tomorrow, Photogramm. Eng. Remote Sens., 72, 1171-1178, 2006.

Xu, E.-Q., Zhang, H.-Q., and Li, M.-X.: Object-Based Mapping of Karst Rocky Desertification using a Support Vector Machine, Land Degrad. Dev., 26, 158-167, 2015.

Yan, X. and Cai, Y. L.: Multi-Scale Anthropogenic Driving Forces of Karst Rocky Desertification in Southwest China, Land Degrad. Dev., 26, 193-200, 2015. 